\title{
Impact of Stark II Rules on Interventional Pain Practices
}

\author{
William A. Sarraille, JD
}

The original Stark Law, commonly referred to as "Stark I," was enacted in 1989. Stark I prohibited a physician from ordering a clinical laboratory test or service from an entity with which the physician, or an immediate family member, had a financial relationship if the test or service was reimbursable by Medicare, unless an exception to the law applies.

The Stark Law was amended in 1993. The amendments are commonly referred to as "Stark II." Stark II extended the referral prohibition to services reimbursable under Medicaid and greatly expanded the list of items and services cov- ered by the law i.e., "designated health services."

HCFA published phase I of the Final Stark Rules on January 4,2001 . These rules dealt with referral definition issues, volume or value of referrals, in-office ancillary services exception, group practice definition, and definitions of designated health services. This article describes phase I of Stark II Final Rules, and its impact on interventional pain medicine practices.

Keywords: Stark II Final Rule, designated health services, group practice, interventional pain medicine
After many delays and much anticipation, the Health Care Financing Administration (HCFA) has released Phase I of its Stark II final rules. Although the final rules are being hailed for the relief they have brought to a series of problems under the Federal Physician Self-Referral Statute, a number of difficult questions remain. This article summarizes the most important portions of the Stark II rules, which promise to reshape physician contracting and compensation in interventional pain physician services.

\section{BACKGROUND}

The original Stark Law, commonly referred to as "Stark I," was enacted in 1989. Stark I prohibited a physician from ordering a clinical laboratory test or service from an entity with which the physician, or an immediate family member, had a financial relationship if the test or service was reimbursable by Medicare, unless an exception to the law applies. The term "financial relationship" includes

From Arent Fox Klinter Plotkin \& Kahn, PLLC, Washington, DC. Mr. Sarraille is a partner in the Health Law Group of Arent Fox and chief counsel to American Society of Interventional Pain Physicians. Address correspondence: William A. Sarraille, JD, 1050 Connecticut Avenue NW, Washington, DC 20036-5339.

Email: sarrailw@arentfox.com. both investment interests and compensation arrangements. Stark I became effective on January 1, 1992.

The Stark Law was amended in 1993. The amendments are commonly referred to as "Stark II." Stark II extended the referral prohibition to services reimbursable under Medicaid and greatly expanded the list of items and services covered by the law i.e., "designated health services" or "DHS". The Stark II expansion had a tremendous effect on interventional pain physicians, precisely because of the breadth of the list of designated heath services added by the amendment. Those services included hospital outpatient and inpatient services, physical therapy services, radiology services, and outpatient prescription drugs. Stark II became effective on January 1, 1995.

\section{PHASE I}

As indicated above, HCFA will issue the final Stark rules in two phases. The rules published on Jan. 4, 2001 represent "Phase I" and are focused mainly on the scope of the referral prohibition, the in-office ancillary services exception for group practices, and certain new exceptions. Phase II, in turn, will focus on the remaining provisions in the statute, largely compensation exception issues and the statute's application to Medicaid. Although a "60-day" hold has been placed on the Stark II regulations by the Bush Administration, no significant change of the Phase I provisions is anticipated. 
Because of the significant changes made in Phase I, HCFA published these final rules with a 90-day comment period. HCFA will accept comments on Phase I until April 4, 2001. The American Society of Interventional Pain Physicians (ASIPP) will be filing comments. According to Phase I, these comments will be incorporated in Phase II, which HCFA claims it will publish shortly afterwards. Obviously, Phase II will not be published until at least the end of the comment period for Phase I, and likely substantially after that. This could create an unfortunate situation where the effective date for the delayed implementation of some Phase I obligations may occur before the Phase II rules are issued, which, in several cases, may be needed to clarify issues that relate to Phase I.

In order to allow for both the comment period and time for providers "engaged in business arrangements affected by Phase I . . to restructure those arrangements to comply" with the final Stark rules, HCFA has generally delayed the effective date of new requirements created by Phase I for one year. Because HCFA also says that the statute and statutory requirements are currently effective, there is a good deal of uncertainty surrounding what requirements are statutory and, therefore, currently in effect, and what requirements are "new" and not yet effective.

\section{REFERRAL DEFINITION ISSUES}

Under Phase I of the Stark regulations, a "referral" means either of the following:

A request by a physician for, or ordering of, or certifying or recertifying of the need for, any designated health service, including a request for a consultation with another physician, as well as any test or procedure ordered by or to be performed by (or under the supervision of) that other physician; or

A request by a physician that includes the provision of any designated health service or the establishment of a plan of care by a physician that includes the provision of such a designated health service, or the certifying or recertifying of the need for such a designated health service.

Phase I of the regulations makes clear that the term "referral" does not include a designated health service ordered and personally performed by the same physician. If an interventional pain physician were to personally perform a radiology technical component (such as fluoroscopy) or a related professional component service, those services would not involve a "referral" within the meaning of the Stark Law. In the preamble to the Phase I regulations, however, HCFA states that services performed by others, including the ordering physician's employee, or other physicians in the practice, are still included in the definition of referral.

Despite this, HCFA noted that it recognizes that, in many cases, services performed by a physician's employees are, for practical purposes, tantamount to services performed by the physician. The example HCFA used is a physician's assistant applying a neck brace ordered by a physician for an individual when the face-to-face physical examination by the physician, indicated the need for the adjusted neck brace. HCFA noted that it specifically seeks comments as to whether services performed by a physician's employees should be treated as the physician's personally performed services. ASIPP will be submitting comments on this issue as well.

HCFA also stated that it was establishing an exception for indirect and oral referrals. An interventional pain physician may have a patient referred by an orthopedic surgeon with whom the pain physician has a financial relationship, but the patient does not say that he was referred by the orthopedic surgeon. When there is no written order or other documentation of the referral, the provider of designated health services will only be held responsible for the indirect or oral referral when it knows or has reason to suspect the identity of the physician who prescribed or ordered the designated health service or made the referral.

HCFA also stated that a referral by a nurse practitioner or physician assistant could be imputed to an employer physician if the physician controls or influences the nonphysician's referral. HCFA noted that these nonphysicians may not always act independently of their employers. Clearly, when these nonphysician services are billed incident to an interventional pain physician's or another physician's services, an imputation will be made.

HCFA further noted that the direction or steering of a patient to an entity does not need to be in writing for a "referral" to occur. Nor does it have to be absolute. Rather, it need only be reasonably intended to result in the patient receiving the service from the entity. HCFA noted that a physician can make a referral of DHS to an entity, even though the referral is first directed or routed through another physician or entity, if the physician has reason to know the identity of the actual provider of the service. 


\section{"VOLUME OR VALUE" OF REFERRALS AND "OTHER BUSINESS GENERATED" STANDARDS}

Virtually all of the noteworthy exceptions to the Stark Law include a requirement that prohibits payments related to the volume or value of referrals or other business generated between the parties. In a significant departure from the proposed rules, HCFA now takes the position that timebased or unit-of-service-based payments do not necessarily violate this requirement and may be protected, so long as the payment per unit is at fair market value at inception and does not subsequently change during the term in any manner that takes into account designated health services referrals. For example, compensation arrangements based upon a percentage of gross revenues, collections, or expenses will not satisfy the requirements of this exception. A compensation arrangement based upon a percentage of a fee schedule could satisfy the exception, if there were a single fixed fee for each service (i.e., there were not multiple payments amounts from different payors). Given the prominence of "percentage" contracts in interventional pain physician and other physician services, this restriction could force major changes in existing compensation arrangements.

In the case of exceptions that include the additional restriction that the payment not take into account "other business generated between the parties," such as in the space and equipment lease exceptions, the per-unit payment also may not take into account any other business, such as an non-federal health care business, generated by the referring physician. Thus, compensation arrangements should be structured to be consistent with fair market value for the work performed, not inflated to compensate for the physician's ability to generate additional revenue.

Unfortunately, Phase I of the final Stark rules does not address the "commercially reasonable even in the absence of referrals" standard that is an additional requirement for some of the Stark Law exceptions. Accordingly, it is unclear if this standard would not be met where, for instance, a per unit approach is taken and the physician involved is responsible for generating a majority of the units with his or her own referrals.

HCFA notes that the fact that a contract requires referrals to certain providers does not vitiate the exception, provided that the contract expressly provides exceptions for situations when the patient expresses a different choice, when the patient's insurer determines the provider, or when the referral is not in the best medical interest of the patient in the physician's judgment. HCFA points out that, even if an arrangement does meet a Stark Law exception, it could still run afoul of the Federal Anti-Kickback Statute.

\section{THE IN-OFFICE ANCILLARY SERVICES EXCEPTION}

The Stark Law's prohibition on referrals does not apply to services that meet the "in-office ancillary services" exception. This exception is the primary mechanism that interventional pain physicians and other physicians use to protect referrals for designated health care services made within their practices. It generally allows interventional pain physicians and other physicians to order designated health services from their own practices so long as (1) the services are personally performed by the ordering physician or another physician member of the ordering physician's group practice or (2) the service is provided by a non-physician within the group practice who is directly supervised by the ordering physician or another physician member of the ordering physician's group practice. The exception contains additional detailed requirements relating to (1) the locations where in-office ancillary services may be performed and (2) how they may be billed, which are discussed below.

In the final rule, HCFA has attempted to administratively simplify the exception, while retaining what HCFA believes was Congress' intent to protect only those services that are actually ancillary to the physician's practice. This effort results in positive changes with respect to the supervision requirements of the exception, but imposes new limits on the locations where services may be furnished. ASIPP pushed aggressively for the changes in the supervision standards.

\section{Scope of Designated Health Services that Can be In-Of- fice Ancillary Services}

The 1998 proposed rule suggested that a DHS would be considered furnished in the location where the service was actually performed or where the patient received and began to use the item. In response to confusion about the applicability of the exception to outpatient prescription drugs and ambulatory infusion pumps, the final rule takes a slightly broader approach to the furnishing of items. The final rule recognizes an item as being furnished when the item is dispensed to the patient in a manner that is sufficient to meet the applicable payment and coverage rules. This new definition, along with changes in the supervision requirements (discussed below), may improve the ability of interventional pain physicians to provide both infusion 
and outpatient drug services.

\section{Direct Supervision}

\section{What Does It Mean to Provide Direct Supervision?}

The statute requires in-office ancillary services to be furnished either (1) personally by the referring physician or another physician member of the same group practice, or (2) by non-physicians who are directly supervised by the referring physician or other physician group member. In keeping with ASIPP's lobbying proposal, the final regulation defines "direct supervision" as that level of supervision that would satisfy the supervision requirements under the applicable Medicare payment or coverage rules for the particular service at issue.

The definition of "direct supervision" adopted under the final rule is a significant change from the proposed regulation and an important victory for interventional pain physicians. In the proposed regulation, HCFA required the physician to be present in the office suite where the services are being provided and (with a very limited exception) to be immediately available throughout the entire service. For interventional pain physicians who must leave their offices and perform procedures in a hospital outpatient department or an ambulatory surgery center, the direct supervision standard, as it was interpreted by HCFA, was a major obstacle and was inconsistent with the supervision called for under the applicable standards of care. For example, simple radiology services may be furnished under general physician supervision.

In responding to the concerns raised by ASIPP and others, HCFA changed, as noted above, the supervision standard under the in-office ancillary services exception to require only that level of supervision otherwise required by the Medicare payment and coverage rules. In a number of cases, such as simple radiology services and clinical laboratory services, the Medicare payment and coverage rules only require general supervision of non-physicians providing those services. General supervision does not require the physician supervisor to be present in the office suite when the service is provided.

Providers should remember, however, this revision to the in-office ancillary service supervision standard has no $\underline{\mathrm{im}}$ pact on physician services that are furnished as incident-to services. In other words, if an interventional pain physician elects to furnish certain DHS as "incident-to services," all the coverage requirements for incident-to services, including the applicable direct supervision standard, must be satisfied.

\section{Who May Provide "Direct Supervision”?}

In the proposed regulation, HCFA proposed eliminating independent contractors as members of a group practice. While this proposal improves the ability of a small physician group to qualify as a group practice (see the discussion below about the definition of a "group practice"), the proposal prohibited independent contractors from being eligible to supervise non-physician employees who were furnishing potential in-office ancillary services. In response to concerns raised about this issue, the final regulation permits independent contractors to supervise in-office ancillary services, if certain conditions are met.

To supervise designated health services, an independent contractor must furnish patient care services to the group practice's patients in the group practice's facilities, under a contractual arrangement with the group practice. Furthermore, the contract must contain the same restrictions on compensation that apply to members of the group practice (discussed later) or it must satisfy the requirements of the personal services exception to the Stark Law. Finally, the arrangement between the group and the independent contractor must comply with the Medicare reassignment rules.

\section{The Building Requirements}

The in-office ancillary services exception also requires that the services be furnished in a building in which the referring physician, or another physician who is a member of the same group practice, furnishes physician services that are unrelated to the furnishing of DHS. Alternatively, if the physician who makes the referral is a member of a group practice, the services may be performed in another building used by the group for the provision of all or some of the group's clinical laboratory services or for the centralized provision of other DHS.

\section{$\underline{\text { Same Building }}$}

The final rule permits in-office ancillary services to be furnished in the same building in which the referring physician or another group practice member furnishes substantial physician services unrelated to the furnishing of DHS payable by any payor. "A building" is defined as any struc- 
ture or combination of structures having a single United States Postal Service street address. It does not include parking lots or parking garages where mobile equipment may be located.

The rule also prohibits the receipt of the DHS (whether covered by private or government payor) from being the primary reason the patient comes in contact with the referring physician or group practice. Highly specialized physicians may find this criterion difficult to satisfy if their practice is focused in areas considered DHS, such as radiology or other imaging services. HCFA states that its intention is to "preclude single service DHS enterprises from the in-office ancillary services exception" and ensure that the exception protects only those services related to the physician's practice.

\section{Centralized Building}

An alternative to the same building requirement is the "centralized building" standard. The final rule permits services to be furnished in a centralized building that is used by a group practice for the provision of some or all of the group practice's clinical laboratory services or other DHS. The centralized building does not need to service all of the group's offices or furnish all of the group's DHS.

The centralized building alternative may only be used when the referring physician is a member of the group practice. It may not be used for services referred by an independent contractor. In-office services referred by independent contractors must be meet the "same building" standard.

The centralized building standard requires the space for furnishing the DHS to be used exclusively by the group, on a full-time basis (7 days per week, 24 hours per day). The ownership or lease of the space must be for at least six months. One significant impact of the new rule is that parttime arrangements of space for the furnishing of DHS, such as one day rentals of MRI or ultrasound laboratories or physical therapy units, will not satisfy the centralized building requirement. If a group wishes to use space on a parttime basis or lease space from another group on a parttime basis, the DHS services must satisfy the same building requirements.

\section{$\underline{\text { Mobile Units }}$}

The preamble discusses the applicability of the building standard to the provision of ancillary services through mobile units. A mobile unit will not satisfy the "same build- ing" standard since the definition of a building excludes parking lots and parking garages where mobile units might be placed. Furthermore, HCFA considers mobile units whose use is shared by multiple physician groups not to be "in-office" services. Nevertheless, HCFA recognizes certain mobile unit arrangements as compliant with the "centralized building" standard. The group practice must exclusively own (or lease) the mobile unit to circulate among its group practice locations.

\section{The Billing Requirements}

The exception imposes limits on who may submit a bill for a DHS. To address how to bill for services of independent contractors, who are physicians in a group practice but not members, HCFA has interpreted the statute to permit billing by a group practice for physicians who are "in the group." The final regulation also permits billing by entities wholly-owned by the physician (or group practice) performing or supervising the services. The wholly-owned requirement may limit the ability of physicians or groups to use the in-office ancillary services exception in shared facility arrangements.

In the past, small group practices and solo practitioners had indicated the efficiencies that sharing certain facilities permitted. While rejecting a suggestion to adopt a new exception for shared facilities, the preamble acknowledges the appropriateness of the in-office ancillary services exception to DHS services furnished in a shared facility. Unfortunately, the exception's use may be hampered by its strict billing limitations which require that the "shared facility" bill in the name of the practice wishing to rely upon the exception.

\section{GROUP PRACTICE DEFINITION}

Among the most troubling aspects of the 1998 proposed rule was its treatment of the definition of a "group practice" for purposes of the Stark Law. This definition is critical because it is, in most cases, a threshold requirement for the all-important in-office ancillary services exception discussed above.

Most of the problems with the 1998 proposed rule's group practice definition resulted from HCFA's efforts to target "sham group practices" and "loose confederations" of physicians bound together - in HCFA's view at least - to circumvent the law's prohibitions. Thus, the proposed rule included a "unified business test" that would have prohibited different accounting and profit distribution systems 
for satellite offices or for different specialties within a group practice. Other proposals would have excluded sole shareholder practices from the definition of a bona fide group, and barred the payment of productivity bonuses that included any portion of a physician's own orders for designated health services (even if the physician personally performed the services). In response to criticism that these proposals would have excluded many bona fide group practices, intruded too far into the financial operations of physician practices, HCFA substantially revised the group practice definition in the final rule.

The final rules create a substantially more flexible "unified business" test that will permit group practices to maintain separate cost centers for different practice locations or specialties, at least with respect to non-designated health services and, in some cases, with respect to designated health services, so long as the compensation method is not directly related to the volume or value of referrals and other conditions are satisfied. To meet the revised unified business test, a group practice must be organized and operated on a bona fide basis as a single integrated business enterprise with legal and organizational integration. While HCFA's new rule sets general parameters indicative of integration, it does not dictate specific compensation practices.

The final rules also allow a group to consist of almost any kind of legally organized entity, owned by virtually any combination of individuals and other entities, provided that there are at least two physicians providing services to patients as group practitioners. As a result, sole shareholder entities will qualify as a group practice, as long the group employs at least one other physician.

As under the proposed rule, independent contractors are no longer considered "members" of a group. This provision helps groups in meeting the so-called "substantially all test" for group practice status, which requires that at least 75 percent of the services of a group's members must be provided through the group, in aggregate. By limiting members to owners and employees of the group, it will be easier for groups that use part-time independent contractor physicians to fulfill this requirement. As indicated above, HCFA also liberalized the direct supervision standard in the in-office ancillary services exception to permit supervision by independent contractors. Under the new rules, groups also may pay productivity bonuses to independent contractor physicians.

The final rules provide additional revisions to the produc- tivity bonus rules, so that group practices may pay physicians in the group bonuses based directly on the services they perform. However, the final rule continues to prohibit groups from paying physicians bonuses based directly on their referrals of designated health services that are performed by someone else.

The final rules also promulgate specific methods for paying productivity bonuses and distributing profits which HCFA deems to be only "indirectly" related to referral income. In other words, if a group practice wants absolute assurance that its bonuses or profit shares are not "directly" related to referrals, the group may employ one of the listed methodologies set forth in the regulations. However, groups are not required to use these methodologies. In fact, the regulations make clear that other methods are acceptable so long as they are reasonable, objectively verifiable and no more than indirectly related to designated health service referrals. HCFA's newfound flexibility, however, does not save the Stark Law's group practice definition from remaining a painfully detailed and highly technical morass.

\section{NEW REGULATORY EXCEPTIONS}

\section{Fair Market Value Compensation}

In the 1998 proposed rule, HCFA proposed a new fair market value exception for compensation arrangements that met certain criteria. Phase I of the final regulation adopts this fair market value compensation exception, with certain revisions. HCFA clarifies and emphasizes that, although there was some confusion regarding the scope of the proposed fair market value exception, it is only intended to cover items or services provided by a physician (or immediate family member) to an entity, not by an entity to a physician. Significantly, HCFA will permit the parties to an arrangement to utilize this exception, even if another exception could potentially apply to the arrangement. In other good news for practitioners, HCFA also eliminated a requirement from the proposal that the written agreement cross-reference all other agreements between the parties.

HCFA also revised the exception to state that an arrangement under the exception must (1) not violate the AntiKickback Statute, (2) comply with an Anti-Kickback Statute safe-harbor, or (3) have been blessed by the Office of Inspector General in the form of an official advisory opinion. If an arrangement does not fit within a safe-harbor or receive an advisory opinion, however, meeting this exception may be an exercise in clairvoyance. This is because a 
determination of a "violation" of the Anti-Kickback Statute requires an understanding of the intent of both parties to the arrangement. HCFA acknowledges this fact but notes that it believes it would be "unusual" for only one party to an arrangement to have the intent to violate the kickback statute.

\section{Non-Monetary Compensation up to $\$ 300$}

In this final rule, HCFA significantly revised its previously proposed de minimis exception to be more flexible in a move that should protect Christmas gifts and the like. HCFA eliminated the previous $\$ 50$ per encounter limit, meaning that the value of a particular gift can be any amount, so long as the annual aggregate value of all gifts from that source to the referring physician does not exceed $\$ 300$. HCFA also added a protective measure that would disqualify from this exception gifts that are solicited by the physicians.

In addition, HCFA eliminated the "similarly situated" standard contained in the original proposal, which would have required that any de minimis compensation be made available to all similarly situated individuals. Because the "similarly situated" standard was intended to ensure that gifts were not given primarily to reward high-referrers, HCFA felt that a better approach was to prohibit gifts that take into account the volume or value of referrals or other business generated between the parties. HCFA also points out that the exception covers gifts to individual physicians, not to groups or entities. This seems an absurd distinction.

HCFA makes explicit that "professional courtesy" is not covered by this or any other exception, and solicits comments on appropriate conditions for such an exception. Accordingly, if the Stark Law would otherwise be triggered, no exception to the Stark Law will protect professional courtesy exchanges, at least at present.

\section{Medical Staff Benefits}

HCFA added a new exception that would allow certain "incidental benefits" of "low value" when provided by hospitals to their medical staffs, such as parking, internet access, and duplication services. Although far from perfect, this new exception is of significant value to hospitals and their medical staff, including interventional pain physicians. HCFA specifically states, however, that medical transcription services and the provision of malpractice insurance and are not covered by this exception. In order to be excepted, the benefit(s) provided from the hospital to the medical staff member must be:

(1) Offered by a hospital to all members of the medical staff without regard to the volume or value of referrals or other business generated between the parties;

Offered only during periods when the medical staff members are making rounds or performing other duties that benefit the hospital and its patients;

Provided by the hospital and used by the medical staff members only on the hospital's main campus;

Reasonably related to the provision of or designed to facilitate the delivery of medical services at the hospital;

Consistent with the types of benefits offered to medical staff members by other hospitals within the same region or comparable regions; and Of "low value," meaning less than $\$ 25$, per occurrence.

\section{DEFINITIONS OF THE DESIGNATED HEALTH SERVICES}

In a welcome display of clarity, HCFA has chosen to define several of the designated health services by listing the applicable CPT and HCPCS codes. Beginning with this final rule, HCFA will list annually in the Federal Register the particular CPT codes that define clinical laboratory services, physical therapy, occupational therapy, radiology and certain other imaging services covered by the Stark Law. Although the regulation contains general definitions of these services, the published list of codes will be controlling.

HCFA excepts from the term "designated health services" those services that would otherwise be considered designated health services but are paid for by Medicare as part of a separate composite payment for a group of services as a separate benefit. For example, HCFA will not apply the prohibition on referrals to services paid for under the ASC rate. Notably, however, certain composite rate services will not be able to meet this exception, including inpatient hospital services.

\section{Professional Services as Designated Health Services}

In the final rules, HCFA clarified its position that the professional components of health services are included under the definition of designated health services. Many 
commenters on the proposed rule had suggested that the professional component of the various services, especially clinical laboratory and radiology services, were not covered, and not intended to be covered, by the self-referral prohibition. HCFA declined to adopt this interpretation or definition, but noted that "as a practical matter" they believed that the professional components of many designated health services will be excluded from the definition of referral, as they would be personally performed by the referring physician.

\section{Radiology and Certain Other Imaging Services}

HCFA has redefined the category of "radiology and certain other imaging services" to clarify what imaging services are included in this category. In particular, HCFA has slightly modified its 1998 proposal to exclude radiology services that were peripheral, incidental, or secondary to a nondesignated health services from the operation of the Stark Law. Under the final rules, any radiology procedures that are integral to the performance of, and performed during, a nonradiology medical procedure are not considered part of this designated health service. X-ray, fluoroscopy, and ultrasound services that are part of invasive procedures requiring the insertion of a needle, catheter, tube, or probe have been excluded from this category (i.e., fluoroscopic guidance in an interventional procedure). However, HCFA warns that such procedures could still be considered designated health services, if they are, for instance, provided in a hospital and are, therefore, inpatient or outpatient hospital services under the Stark Law.

\section{Outpatient and Inpatient Hospital Services}

HCFA largely retained the proposed definitions of outpatient and inpatient hospital services. Of particular importance, however, HCFA discusses at length "under arrangements" relationships which some interventional pain physicians are entering into in the wake of the collapse of Medicare outpatient pain procedure rates. In "under arrangements" relationships, a hospital outsources a portion of its services to an outside third party that provides the services. The hospital pays the outsourced provider, bills Medicare for the services, and remains ultimately responsible for the services.
HCFA noted the pervasive nature of many of these arrangements and realized that prohibiting them on the grounds that the physician was an "owner" of the outsourced entity providing the service would significantly disrupt patient care. HCFA stated that it will treat under arrangements relationships between hospitals and physician owned entities as only "compensation relationships," which means they will be protected if they meet an applicable exception, such as a space lease or personal service exception. It should be possible to protect most of those relationships under these exceptions. HCFA cautioned, however, that it may reconsider its decision if it suspects the arrangements are abused. HCFA also warned hospitals and physician groups that such relationships must still comply with the Anti-Kickback Statute.

HCFA also clarified that the professional services of physicians, physician assistants, and certain other practitioners are not considered inpatient or outpatient hospital services (and thus not "designated health services"), if Medicare reimburses the services independently and not as part of the inpatient or outpatient hospital service.

\section{Outpatient Prescription Drugs}

Outpatient prescription drugs are considered designated health services subject to the general prohibition on referrals. In Phase I, HCFA revised the definition of outpatient prescription drugs to make clear that it includes all prescription drugs covered by Medicare Part B. In the preamble to Phase I, HCFA noted that the breadth of its definition of outpatient prescription drugs is ameliorated to a large extent by its expansion of the in-office ancillary services exception, which includes greater flexibility with respect to the direct supervision requirement.

\section{CONCLUSION}

With the Department of Justice having recently announced that it is investigating over fifty False Claims Act cases that include allegations of Stark Law violations, Stark Law compliance is all the more critical in the wake of the Stark II final rules. 